\title{
ANTENATAL HEALTH CARE; \\ A LITERATURE REVIEW OF ANTENATAL AND POSTNATAL HEALTH CARE UTILIZATION IN PAKISTAN
}

1. PhD Scholar,

Department of Sociology,

University of Sargodha, Sargodha.

2. Assistant Professor,

Department of Sociology

GC. University Faisalabad.

3. Lecturer,

Department of Sociology

GC. University Faisalabad.

4. PhD Scholar,

Department of Sociology

GC. University Faisalabad.

Correspondence Address:

Nazia Malik

Assistant Professor

Department of Sociology

GC. University Faisalabad.

naaziamalik@gmail.com

Article received on:

02/12/2016

Accepted for publication:

25/02/2017

Received after proof reading:

06/04/2017
Muhammad Asim', Nazia Malik², Saira Siddiqui ${ }^{3}$, Waseem Nawaz ${ }^{4}$, Farman Ali

ABSTRACT... Background: Prenatal and postnatal health care utilization services are imperative strategy to decrease maternal morbidity and mortality. One in 38 Pakistani women dies from pregnancy related causes as compared to 1 in 230 women in Sri Lanka. Objectives: The objective of the present study is to know about the pattern and trends of utilization of antenatal and postnatal health care services by mothers in Pakistan. Study design: Descriptive systematic literature review. Material and methods: The relevant literature was systematically searched through different key words related to antenatal and postnatal health care utilization services in Pakistan through different online research engines to accomplish this study. Results: Twenty five research articles were included in this review article. It was found that last two decades, we cannot achieve the optimum progress towards antenatal and postnatal health care utilization services. The problem is much severe in rural areas of across the country, where a number of socio-cultural and program factors hinders women to utilize the basic health services. Mother's education, household income, autonomous at household decision making and birth order are the significant factors that to utilize the antenatal and postnatal care in Pakistan. Conclusion: There should be need to aware the mother about the importance of prenatal and postnatal visits. In rural areas, government should give some economic incentive for prenatal and postnatal visits. Furthermore, government should take necessary steps to tackle the problem by providing the easy access to the health care facilities.

Key words: Antenatal and postnatal care, reproductive health, and mother's education.

Article Citation: Asim M, Malik N, Siddiqui S, Nawaz W, Ali F. Antenatal health care; A literature review of antenatal and postnatal health care utilization in pakistan. Professional Med J 2017;24(4):495-499. DOI: 10.17957/TPMJ/17.3803

\section{INTRODUCTION}

Prenatal and postnatal health care utilization services are imperative strategy to decrease maternal morbidity and mortality. Prenatal care is the optimistic approach to overcome the prospective hindrance before and after delivery. Regardless of the complications, it is indispensable for pregnant women to visit the health facility for antenatal care. Maternal health care utilization services are essential for maternal and neonate health and safety during pregnancy, delivery and the postnatal period. ${ }^{1,2}$ It is estimated that over half a million women die of pregnancy related reasons around the globe. In low income countries, primary cause of death in childbearing age is pregnancy related complications. ${ }^{3}$

Maternal mortality rate in Pakistan is very high as compared to other neighbouring countries having similar socio economic status. Pakistan is listed in one of six countries that are contributing more than half of all maternal mortality across the globe. ${ }^{4}$ In Pakistan maternal mortality rate is $260 / 100,000$ reported highest in South Asian region. One woman out of sixteen is dying from pregnancy related diseases in developing countries. ${ }^{5}$ Pakistan has the alarming situation with regard to the maternal health. One in 38 Pakistani women dies from pregnancy related causes as compared to 1 in 230 women in Sri Lanka. ${ }^{6}$ Each year, in Pakistan, about 30,000 women is dying due to the birth related complications. Some 0.3 million women developed pregnancy related disabilities each year due to the lack of antenatal and postnatal care services. ${ }^{7}$

It is imperative for mothers to undergo recommended prenatal care and postnatal care, 
even if they don't feel impediment during and after pregnancy. Health care utilization services are significant and must be accomplished during pregnancy, delivery and in postpartum period to make sure the health status of maternal and new born child ${ }^{1,2}$ According to Pakistan Demographic and Health Survey $(2008-09)^{8}$ only $65 \%$ of the mothers for the first time visited for antenatal health care service and only on fourth $26 \%$ mothers got four recommended visits for prenatal health care services.

It is recommended that mother and neonate must be go through the Postnatal consultation visits between the forty two days after delivery for physical examination, post-delivery care, breastfeeding, and immunization tips. But most of the mothers are reluctant to get these health care services because of a number of socio cultural reasons. ${ }^{9,10}$ To evade pregnancy linked concerns, it is recommended by the World Health Organization (WHO) that every pregnant woman get at least four prenatal visits from first trimester to termination the delivery. ${ }^{34}$ According to the recommendation of WHO more than half almost $55 \%$ of mother received prenatal care around the world. But only $37 \%$ of the mothers in low income countries received recommended prenatal care visits. ${ }^{11}$ So, the situation regarding prenatal and postnatal care is not satisfactory in low income nations, especially in Pakistan. The objective of the present study is to know about the pattern and trends of utilization of antenatal and postnatal health care services by mothers in Pakistan.

\section{METHODS}

For the purpose of writing this review article, the researcher reviewed the 70 articles and after the careful review the 28 relevant articles were included in this research. The research design is followed by previous used methodology for antenatal health care field researches.

A systematic search of national and international literature especially from developing countries was undertaken from peer reviewed indexed journals, including Pub Med, BMC, JPH and MEDLINE. The most up to date data were used for accessing the prevailing situation. Official and non-officials research documents and reports World Health Organization (WHO), United Nations Children's Fund (UNICEF), Pakistan Demographic and Health Survey (PDHS), were searched through Google and Google Scholar through different key words. The research design of present study is followed by previous used methodology for public health domain researches of Asim ${ }^{5}$ Hirani ${ }^{12}$ and Methew. ${ }^{13}$

\section{DISCUSSION}

Trends of prenatal and postnatal care in Pakistan

National Institute of Population Sciences ${ }^{14}$ pointed out that one woman in every eighty nine has a threat of dying due to reproductive linked cause in Pakistan. Antenatal and postnatal health care utilization services are significant indicators to reduce maternal and neonatal morbidity and mortality. Mother health care services during pregnancy, delivery and postnatal period are remarkable benchmark for the health and safety for maternal and neonatal health. ${ }^{1,2}$ In normal situation WHO suggests at least four antenatal consultation during pregnancy in ordinary circumstances. Only more than half $53 \%$ of pregnant women across the world went for at least four antenatal consultation. The statistics is much drastic in low income countries, where only $36 \%$ women went for antenatal consultation. ${ }^{15}$ According to Memon ${ }^{16}$ who pointed out that antenatal and postnatal care services have the major implications for mother and child health outcomes. Postnatal care visits provide window of the opportunity to disseminate the message to educate the mother about better care for herself and neonate. According to $\mathrm{DHS}^{17}$ in Pakistan, slightly more than half i.e. $52 \%$ of births report to take place at home. Traditional birth attendants (TBAs) assist $41 \%$ deliveries, while $6 \%$ of deliveries assist by the relatives and friends. Accessibility and selection of a qualified health care provider make sure health status of pregnant women. Women seeking care during pregnancy from experienced care providers has not considerably improved in Pakistan. According to the national Nutrition Survey ${ }^{18} 58.9 \%$ mothers got antenatal care from qualified and skilled health care providers. 
Due to the dearth of antenatal and postnatal health care consultation trends, Pakistan has the highest maternal and neonatal mortality around the globe. Hazir ${ }^{19}$ said that Pakistan has the third highest neonatal deaths and the first in the rank of still birth in the world. ${ }^{20}$ According to the Memon ${ }^{21}$ neonatal mortality remained unchanged for the last two decades at 55 deaths per 1000 live births in Pakistan.

In Haripur, Khadduri22 pointed out that the women only go for antenatal visits, if she feels some complications. Kaphle ${ }^{23}$ in Nepal found only $65.54 \%$ have completed ANC visit at least four times and $29.05 \%$ have received counselling on new born care during pregnancy. The current situation of the maternal reproductive health care and antenatal and postnatal health care utilization services are underprivileged and there is enough space to work for improving the maternal and child health care in Pakistan.

Ayaz and Saleem ${ }^{24}$ stated that $54 \%$ women had four postnatal visits and majority of the mothers i.e. $70 \%$ in Karachi got antenatal care by skilled health care providers. Another study in Karachi, Ali and Ather ${ }^{25}$ examined $75.4 \%$ mothers got antenatal care and more than half $52 \%$ took consultation from certified professionals and only one fourth mothers had postnatal visits. According to Batool ${ }^{26}$ in Faisalabad $74 \%$ pregnant mothers have only one antenatal visit. Similar finding found by Asim et al, ${ }^{27}$ who stated that majority of the mothers $79 \%$ got at least one prenatal visit in district Faisalabad and 18\% deliveries took place at home that was assisted by TBAs.

\section{Geographical disparity to utilize Prenatal and postnatal care}

According to the most recent Pakistan social and living standard measurement survey ${ }^{28}$ seventy three percent pregnant mothers utilize the prenatal health care service as compared to $69 \%$ in 2013. Pre-natal check-ups trends have been increased in rural and urban dwellings. It was found that $86 \%$ antennal coverage was reported in urban areas whilst $67 \%$ in rural areas. Punjab has been reported the highest coverage rate with $78 \%$ and Baluchistan showed the lowest coverage with $47 \%$. The trend is much satisfactory in capital territory of Islamabad where 95\% consulted for pre-natal care visits. According to another recent national representative survey ${ }^{35}$ PDHS, almost $73 \%$ of mothers reported to have at least one antenatal visit from skilled health providers. Only $37 \%$ women determine four Antenatal care (ANC) visits. As for as postnatal care concern $38 \%$ women did not go for postnatal consultation and $60 \%$ women went for postnatal care within forty eight hours after delivery. Antenatal coverage trend is highest among younger mothers less than 35 years old and in urban settlements. In Baluchistan antenatal care service utilization from skilled birth attendance is low only $31 \%$ and $78 \%$ in Punjab and Sindh. Mother's education is positively associated with umber of antenatal visits from skilled birth attendance. ${ }^{35}$

Antenatal health care utilization has gigantic significance for the health of pregnant women. Unfortunately, there has been no progress reported in the proportion of women seeking antenatal care since last two decades. According to the findings of NNS ${ }^{18} 2011$ only $62.0 \%$ women got ANC. The data of NNS clearly pointed out that there is huge disparity is observed in rural and urban areas, whereas $81.4 \%$ in urban areas and $53.7 \%$ sought antenatal care in rural areas. Provincial data depicted those women who sought care during pregnancy was $66.5 \%$, $61.6 \%, 55.7 \%$, and $47.1 \%$ in Punjab, Sindh, KPK and Baluchistan respectively. The trend for consultation for the purpose of prenatal care was also examined across the Pakistan. It was found that majority of pregnant women in Punjab and Sindh got consultation from private clinics/hospitals, whilst interestingly the trend is reverse in KPK and Balochistan where majority of women visited public health facilities/hospitals for antenatal consultations. There are commonly three major consulted sources were documented i.e. private clinics/hospitals with $57 \%$, government health facilities/hospitals with $31 \%$ followed by Leady Health Workers with $5 \%$ and $4 \%$ by traditional birth attendant. ${ }^{28}$

Prenatal and postnatal care in socio-economic context 
The study revealed that women and their husband's education, child birth order, type of profession and women autonomy are the major determinants of maternal health seeking behaviour in Pakistan. ${ }^{29}$ Munir also pointed out that mothers, who had better education, indicate positive inclination to have maternal health care services. Furthermore, the mothers who had primary education and above are 3\% more likely to receive antenatal and postnatal health care as compare to illiterate. According to Faiz et $\mathrm{al}^{30}$ the major hindrances to utilize the antenatal care services are illiteracy, mobility issues, non-cooperative behaviour of in laws, lack of resources and time. It is also found that there is a direct relationship between educational status of the mother and her husband and better access towards maternity care. Budhwani and Hearld ${ }^{31}$ pointed out that education and wealth, birth order, distance to health facility are the major predicators to utilize maternal health care in Pakistan. Higher birth order directly linked to the lower the accessing prenatal, delivery, or postnatal care was reported in the study. Another study from Punjab Pakistan Akhtar et $\mathrm{al}^{32}$, found that education of mothers and husbands significantly associate with antenatal and postnatal health care utilization services. Hou and $\mathrm{Ning}^{33}$ examined the impact of women decision making at household and access to maternal health care services. They found that women's decision-making power has a significant and positive impact on access to maternal health care services. The opposite effect was observed where the male had more power at household level.

Copyright(C) 25 Feb, 2017.

\section{REFERENCES}

1. Frost, J.J. 2001. Public or private providers? U.S. women's use of reproductive health services. Family Planning Perspectives, 33(1): 4-12.

2. Khan, N., S. Khan, N. Khan and S. Khan. 2013. Factors Affecting Utilization of Maternal and Child Health Services: District Swat KPK. Pakistan International Journal of Innovative Research and Development, 2(8): 217-227.

3. Patton, G.C., Viner, R.M., Linh, L.C., Ameratunga, S., Fatusi, A.O., et al. Mapping a global agenda for adolescent health. Journal of Adolescent Health; 2010;
47(5): 427-432.

4. Hogan, M. C., Foreman, K. J., Naghavi, M., Ahn, S. Y., Wang, M., Makela, S. M., et al. (2010). Maternal mortality for 181 countries, 1980-2008: A systematic analysis of progress towards Millennium Development Goal 5. The Lancet, 375, 1609-1623.

5. Asim M, Mahmood B, Sohail M M. Infant health care; practices in Pakistan: a systematic review. Professional Med J 2015; 22(8):978-988.

6. Ahmad, MS. Socio-economic Determinants of Maternal Healthcare Behavior: Evidence from Pakistan. School of Social Sciences and Humanities (S3H) National University of Sciences and Technology (NUST) Sector H-12, Islamabad, Pakistan.

7. Akhtar N. Factors Affecting Utilization of Antenatal and Postnatal Services in Punjab, Pakistan (Doctoral dissertation, University Of Agriculture, Faisalabad).

8. Pakistan Demographic and Health Survey (PDHS). National Institute of Population Studies Islamabad, Pakistan. 2007.

9. Ejaz, S. and K. Ahmad. 2013. Postpartum care utilization among primigravida: $A$ study in rural Punjab, Pakistan. Research on Humanities and Social Science, 3(4):35-45.

10. United Nations. 2002. World programme of action concerning disabled persons. Retrieved on July 25, 2013 from www.un.org/esa/socdev/enable/diswpa01. htm.

11. WHO. 2013. Antenatal Care. Retrieved on Oct. 23, 2016 from:http://www.who.int/gho/maternal_health/ reproductive_health/antenatal_care_text/en.

12. Hirani SAA. Malnutrition in Young Pakistani Children. J Ayub Med Coll Abbottabad 2012; 24(2).

13. Mathew, J.L. Inequity in childhood immunization in India: a systematic review. Indian Pediatric. 2012; 49(3):203-23.

14. National institute of population Science NIPS. Reproductive health issues in Pakistan. Islamabad, Pakistan.2010.

15. World Health Organization (WHO). Provision of effective antenatal care: standards for maternal and neonatal care. Geneva, Switzerland. 2006.

16. Memon ZA, Khan MI, Soofi S, Muhammad S, Bhutta ZA. A cross sectional survey of newborn care practices in rural Sindh, Pakistan: implications for research and policy. J Neonatal Perinatal Med. 2013; 6(2):137- 
44.

17. World Health Organization (WHO). Provision of effective antenatal care: standards for maternal and neonatal care. Geneva, Switzerland. 2006.

18. National Nutrition Survey NNS. Planning Commission, Planning and Development Division. Government of Pakistan. 2011.

19. Hazir, T. Tracking Neonatal Mortality Trends in Pakistan: The Challenges and Way Forward. JSOGP. 2014; 4(2):61-64.

20. Anonymous, 2011. Caesarean section NICE clinical guideline. National Collaborating Centre for Women's and Children's Health. Royal College of Midwife.

21. Memon, M. Survey shows high infant and child mortality in Pakistan. The Hindu. February 23, 2014. http://www.thehindu.com/news/international/southasia/survey-shows-high-infant-and-child-mortality-in pakistan/article5719435.ece.

22. Khadduri R, Marsh DR, Rasmussen B, Bari A, Nazir R and Darmstadt GL. Household knowledge and practices of newborn and maternal health in Haripur district, Pakistan. Journal of Perinatology.2008; 28:182-187.

23. Kaphle HR, Yadav DK, Neupane N, Sharma B, Yadav DK, Poudel SK. Newborn Care Practices in Rural Communities of Nawalparasi District, Nepal. JHAS, 2013; 3(1):35-39.

24. Ayaz A, Saleem S. Neonatal Mortality and Prevalence of Practices for Newborn Care in a Squatter Settlement of Karachi, Pakistan: A Cross-Sectional Study. PLoS ONE. 2010; 5(11): e13783. doi:10.1371/ journal.pone.0013783.

25. Ali TS, Ather F. Prevalence of perceived heavy postpartum hemorrhage and its associated factors among married mothers in squatter settlements of Karachi. Khyber Med Univ J 2013; 5(1): 3-8.

26. Batool, Z. Socio-Cultural Factors Affecting Anemia and its Effects on Mother, Child Health in the Rural Areas of District Faisalabad, Punjab, Pakistan. PhD Published thesis, Department of Rural Sociology, University of Agriculture, Faisalabad. 2010.

27. Asim M, Sohail MM, Manj YN. Reproductive health issues of mothers; A study in Faisalabad. Professional Med J 2015; 22(9):1164-1169. DOI: 10.17957/ $\mathrm{TPMJ} / 15.2851$.

28. Pakistan Social and Living Standards Measurement Survey (PSLM). Government of Pakistan. Statistics Division, Federal Bureau of Statistics, Islamabad. 2011.

29. Dar, SS. Socio economic determinants maternal health behavior in Pakistan: An instrumental variable approach. M.Phil Dissertation, Lahore school of Economic, Pakistan. 2013.

30. Faiz S, Batool Z, Ejaz S, Rashid A. Maternity care services; accessibility among rural women in district Faisalabad. Professional Med J 2016; 23(6):721-726. DOI: $10.17957 / T P M J / 16.3346$.

31. Budhwani H, Hearld KR, Harbison H. Individual and Area Level Factors Associated with Prenatal, Delivery, and Postnatal Care in Pakistan. Maternal and child health journal. 2015 Oct 1; 19(10):2138-46.

32. Akhtar N, Akhtar S, Zafar Ml, Ali T. Impact of Education on the Utilization of Antenatal and Postnatal Services in Punjab, Pakistan. Pakistan Journal of Social Sciences (PJSS). 2013 Dec 1; 33(2):463-70.

33. Hou X, Ma N. The effect of women's decision-making power on maternal health services uptake: evidence from Pakistan. Health policy and planning. 2013 Mar 1; 28(2):176-84.

34. Beeckman, K., F. Louckx and, K. Putman. 2011. Predisposing, Enabling and Pregnancy Related Determinants of Late Initiation of Prenatal Care. Maternal and Child Health Journal, 15(7): 1067-1075.

35. Pakistan Demographic and Health Survey (PDHS). National Institute of Population Studies Islamabad, Pakistan. 2007.

\section{AUTHORSHIP AND CONTRIBUTION DECLARATION}

\begin{tabular}{|c|c|c|c|}
\hline Sr. \# & Author-s Full Name & Contribution to the paper & Author $=$ s Signature \\
\hline 1 & Muhammad Asim & $\begin{array}{l}\text { Introduction and Reivew of } \\
\text { Literature }\end{array}$ & 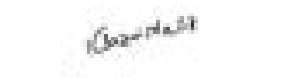 \\
\hline 2 & Nazia Malik & Methodology & \\
\hline 3 & Saira Siddiqui & Results and Discussion & \\
\hline 4 & Waseem Nawaz & $\begin{array}{l}\text { References and review of } \\
\text { literature }\end{array}$ & \\
\hline
\end{tabular}

